\title{
ASSESSMENT OF FEEDING PRACTICE AMONG MOTHERS ATTENDING THE IMMUNIZATION CLINIC OF UCMS HOSPITAL, NEPAL: A CROSS-SECTIONAL STUDY
}

\author{
Binod Kumar Gupta, ${ }^{1}$ Raju Kafle, ${ }^{1}$ Nagendra Chaudhary ${ }^{1}$
}

\begin{abstract}
INTRODUCTION

Practice of exclusive breast feeding has dramatically reduced infant mortality in developing countries due to the reduction of diarrhea and infectious diseases. We conducted a study to assess the feeding practices among mothers with children less than 12 months of age attending the immunization clinic of UCMS hospital, Nepal.
\end{abstract}

\section{MATERIAL AND METHODS}

A hospital based cross sectional study was carried out in the immunization clinic of Pediatric department of UCMS, Nepal for a period of four months. Mothers having of child aged between $0=12$ months were included in the study. Sample size was 372 which was based on the number of mothers visiting Pediatric OPD for immunization of their child of age group 012 months during the duration of the study. Mothers were interviewed by using a pre-validated structured questionnaire. Data was analyzed by using SPSS version-20 software and presented by descriptive statistics as frequency and percentages.

\section{RESULTS}

Most of the children were above six months, $56.5 \%$ were of $7-12$ months of age group. Exclusive breastfeeding was done in $48.4 \%$ children for first six months. Maximum population preferred hospital as their mode of delivery. $93.5 \%$ mothers opted for hospital as their place of delivery. About $23.4 \%$ mothers were illiterate. Night feeding was practiced by $96.2 \%$ mothers.

\section{CONCLUSION}

Knowledge regarding the proper feeding practice is good in mothers. Breast feeding awareness must be spread among mothers by workshops and health education programs.

\section{KEYWORDS}

Breast Feeding, Immunization, Vaccination.

1. Department of Pediatrics, Universal College of Medical Sciences, Bhairahawa, Nepal

DOI: https://doi.org/10.3126/jucms.v9i02.41985

For Correspondence

Dr Binod Kumar Gupta

Department of Pediatrics

Universal College of Medical Sciences

Bhairahawa, Nepal

Email:drbinodkgupta@hotmail.com 


\section{INTRODUCTION}

Practice of breast feeding on this earth dates back to more than million years. The value for breast milk is clearly shown in the oldest book "Charaka Samhita". The World Health Organization recommends the practice of exclusive breastfeeding of infants for the first six months after birth and to continue breastfeeding with supplementary diet up to two years or more. ${ }^{1}$ It offers infants and young children complete nutrition, early protection against illness and promote growth and development of the baby. ${ }^{2}$ Non-breast fed baby is 15 times more likely to get diarrhea and is three times more likely to get respiratory infection. Practice of exclusive breast feeding has dramatically reduced infant mortality in developing countries due to reduction in diarrhea and infectious diseases. ${ }^{3}$ Breast feeding is nearly universal in Nepal and the median duration of breast-feeding is long (33 months). According to a published survey, a major barrier to successful in hospital breast-feeding is inconsistency in information and nursery practices related to breastfeeding management. ${ }^{4}$ Human milk is the ideal nourishment for infants' survival, growth, and development. Particularly in unhygienic conditions, however, breast milk substitutes carry a high risk of infection and can be fatal in infants. ${ }^{5}$ Feeding practice among mothers plays a crucial role in the proper development of an infant. Nepal is a low and middle income country. Studies focusing on the feeding status of babies aged less than six months have not been assessed adequately in the Western part of the country. Hence, this cross-sectional study was aimed to determine the feeding practices among mothers with children less than twelve months of age attending the immunization clinic of UCMS hospital, Nepal.

\section{MATERIAL AND METHODS}

A hospital based cross sectional study was carried out in the immunization clinic of Pediatric department of UCMS, Nepal for a period of four months. Mothers of child aged 0-12 months were included in the study. Data collection was done from December 2020 to 28 March 2021. Informed verbal and written consent was obtained from the parents of the babies enrolled in the study. The study was approved by the Institute Review Committee (ref no UCMS/IRC/ 113/20). Sample size was collected by using convenient sampling. All mothers who were attending immunization clinic for vaccination of their child and had children less than 12 months of were included in the study. Sample size was 372 which was based on the number of mothers visited pediatric ward for immunization of their child of age group $0-12$ months during the duration of the study. Pilot study was done on $5 \%$ volunteer mothers who have similar characteristics with study population. The data of the pilot study was not included in the study. After pilot study, some questions were modified. Mothers were asked to stay after vaccination of their infants to look for any untoward effects of vaccination. A written consent was taken from the mothers before starting the study. Mothers were interviewed by using a pre-validated structured questionnaire. Mothers were assessed on feeding practices followed by them with the help of questionnaire. Questionnaire consisted of demographic details of mothers and 13 questions regarding breastfeeding practices. The collected data was compiled in Microsoft excel. Data was analyzed by using SPSS version-20 software and presented by descriptive statistics as frequency and percentages.

All the mothers having children less than 12 months of age attending the immunization clinic of UCMS hospital, Nepal were included in the study, whereas all those who showed noncooperative attitude or didn't give consent for participation in the study were excluded.

\section{RESULTS}

A cross-sectional study was done on 372 mothers having children less than 12 months of age who were attending the immunization clinic of UCMS hospital, Nepal. Biological characteristics of children are shown in Table 1. 52.2\% children were male and $47.8 \%$ were female. Most of the children were above 6 months. $56.5 \%$ were of $7-12$ months of age group. Majority of study population belonged to middle/lower middle socio-economic status followed by lower/upper lower, upper/middle, lower and upper. 12.4\% were of upper class and $15.1 \%$ were of lower class (Figure 1 ). Demographic details of mothers are shown in Table 2. Merely a small percentage of mothers i.e. $9.9 \%$ belonged to $35-44$ years of age group and 54.8\% were of 21-24 years. Maximum of mothers were of Hindu religion and minimum were of Christian, 44.6\% were Muslims and 1.6\% were Buddhist. In the present study, $52.7 \%$ were living in joint family. Mode of delivery was normal in $68.3 \%$ of mothers.

Maximum population preferred hospital as their mode of delivery. Among them $93.5 \%$ mothers opted for hospital as their place of delivery. $23.4 \%$ mothers were illiterate. Only $2.4 \%$ mothers were professor/honours and $24.5 \%$ were having primary school certificate. Only $28.8 \%$ were employed. $71.2 \%$ were housewife.

Practices regarding breastfeeding followed by mothers are shown in Table 3. In 58.3\% mothers breastfeeding was started after 1 hour of baby birth. $97.3 \%$ mothers gave colostrum to their child. Prelacteal feed was given in $57.3 \%$ children. Exclusive breastfeeding was done in $48.4 \%$ children for first 6 months. Night feeding was practiced by $96.2 \%$ mothers. $69.4 \%$ mothers informed their doctors about lactation status before obtaining prescription for drugs. About 57.5\% mothers continued breastfeeding during their sickness as well. $68.3 \%$ mothers didn't give water to their child during first 6 months. Out of $31.7 \%$ mothers who gave water to their child during first 6 months, majority of them i.e. 19.9\% gave during with some medication. Bottle feeding was practiced by $80.6 \%$ mothers. 22.3\% mothers practiced Katori -spoon feeding. Formula feeding was given by $70.7 \%$ mothers. Only a small number of mothers $(28.8 \%)$ mothers gave pacifiers to their child. 
Table 1. Biological characteristics of children $(n=372)$

\begin{tabular}{llll}
\hline Variable & & Number & Percentage \\
\hline 1.Gender & Male & 194 & 52.2 \\
& Female & 178 & 47.8
\end{tabular}

2. Age (in months)

\begin{tabular}{lll}
$0-6$ & 162 & 43.5 \\
$7-12$ & 210 & 56.5 \\
\hline
\end{tabular}

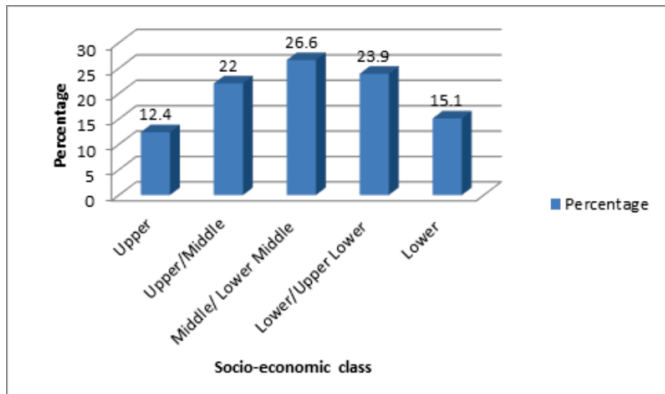

Figure 1. Distribution of study population on the basis of socio-economic status

Table 2. Socio-demographic profile of mothers

\begin{tabular}{rll}
\hline \multicolumn{1}{l}{ Variable } & Number & Percentage \\
\hline Age (in years) & & \\
$21-24$ & 204 & 54.8 \\
$25-34$ & 131 & 35.3 \\
$35-44$ & 37 & 9.9
\end{tabular}

Religion

$\begin{array}{lll}\text { Hindu } & 198 & 53.3 \\ \text { Muslim } & 166 & 44.6 \\ \text { Christian } & 2 & 0.5 \\ \text { Buddhist } & 6 & 1.6\end{array}$

Type of family

$\begin{array}{lll}\text { Nuclear } & 176 & 47.3 \\ \text { Joint } & 196 & 52.7\end{array}$

Mode of delivery

$\begin{array}{lll}\text { Normal } & 254 & 68.3 \\ \text { Cessarian section } & 118 & 31.7\end{array}$

Place of delivery

$\begin{array}{lll}\text { Home } & 24 & 6.5 \\ \text { Hospital } & 348 & 93.5\end{array}$

Education

$\begin{array}{lll}\text { Illiterate } & 87 & 23.4 \\ \text { Primary school certificate } & 91 & 24.5 \\ \text { Middle school certificate } & 51 & 13.7 \\ \text { High school certificate } & 23 & 6.2 \\ \text { mediate/ Post high school diploma } & 64 & 17.2 \\ \text { Graduate/Postgraduate } & 47 & 12.6\end{array}$

Table 3. Showing mothers' practices regarding breast feeding

\begin{tabular}{|c|c|c|}
\hline Questions & Number & Percentage \\
\hline \multicolumn{3}{|l|}{ 1. Breast feeding was started } \\
\hline a) Within 1 hour & 155 & 41.7 \\
\hline b) After 1 hour & 217 & 58.3 \\
\hline \multicolumn{3}{|l|}{ 2. Colostrum was given } \\
\hline a) Yes & 362 & 97.3 \\
\hline b) No & 10 & 2.7 \\
\hline \multicolumn{3}{|l|}{ 3. Prelacteal feed was given } \\
\hline a) Yes & 213 & 57.3 \\
\hline b) No & 159 & 42.7 \\
\hline \multicolumn{3}{|l|}{$\begin{array}{l}\text { 4. Exclusive breast feeding } \\
\text { was done for first } 6 \text { months }\end{array}$} \\
\hline b) No & 192 & 51.6 \\
\hline $\begin{array}{l}\text { 5. Night Feeding Practiced } \\
\text { a) Yes }\end{array}$ & 358 & 96.2 \\
\hline b) No & 14 & 3.8 \\
\hline \multicolumn{3}{|l|}{$\begin{array}{l}\text { 6. Do you inform doctors } \\
\text { about lactation status before } \\
\text { obtaining prescription for } \\
\text { drugs. }\end{array}$} \\
\hline \multicolumn{3}{|l|}{$\begin{array}{l}\text { 7.Continuation of } \\
\text { breastfeeding when mother } \\
\text { is sick }\end{array}$} \\
\hline a) Yes & 214 & 57.5 \\
\hline b) No & 158 & 42.5 \\
\hline \multicolumn{3}{|l|}{$\begin{array}{l}\text { 8. Do you give water during } \\
\text { first } 6 \text { months }\end{array}$} \\
\hline a) Yes & 118 & 31.7 \\
\hline b) No & 254 & 68.3 \\
\hline \multicolumn{3}{|l|}{$\begin{array}{l}\text { 9. If water is given, is it } \\
\text { given? }\end{array}$} \\
\hline $\begin{array}{l}\text { a) only during with some } \\
\text { medications }\end{array}$ & 74 & 19.9 \\
\hline $\begin{array}{l}\text { b) Only during diarrhea and } \\
\text { vomiting? }\end{array}$ & 36 & 9.7 \\
\hline c) for feeding and thirst & 8 & 2.1 \\
\hline $\begin{array}{l}\text { purpose } \\
\text { d) not given }\end{array}$ & 254 & 68.3 \\
\hline \multicolumn{3}{|l|}{$\begin{array}{l}\text { 10. Bottle feeding done or } \\
\text { not? }\end{array}$} \\
\hline a) Yes & 300 & 80.6 \\
\hline b) No & 72 & 19.4 \\
\hline \multicolumn{3}{|l|}{$\begin{array}{l}\text { 11. Katori-spoon feeding } \\
\text { done or not? }\end{array}$} \\
\hline a) Yes & 83 & 22.3 \\
\hline b) No & 289 & 77.7 \\
\hline \multicolumn{3}{|l|}{$\begin{array}{l}\text { 12. Formula feeding given or } \\
\text { not }\end{array}$} \\
\hline a) Yes & 263 & 70.7 \\
\hline b) No & 109 & 29.3 \\
\hline \multicolumn{3}{|l|}{ 13. Pacifiers given or not? } \\
\hline a) Yes & 107 & 28.8 \\
\hline
\end{tabular}




\section{DISCUSSION}

A cross-sectional study was done on 372 mothers having children less than 12 months of age who were attending the immunization clinic of UCMS hospital, Nepal. In our study, $52.2 \%$ children were male and $47.8 \%$ were female. In a study done by Maiti A, ${ }^{1}$ the male child was having a higher percentage $(52.80 \%)$ of vaccination coverage than the female child. In our study most of the children were above 6 months. $56.5 \%$ were of 7-12 months of age group. In a study done by Chaudhary $\mathrm{RN}^{4}{ }^{4} 77.5 \%$ of children were of 6-12 months of age. Majority of study population belonged to middle/lower middle socio-economic status followed by lower/upper lower, upper/middle, lower and upper. $12.4 \%$ were of upper class and $15.1 \%$ were of lower class. In a study done by Chakraborty $\mathrm{N}^{6}{ }^{6}$ most of the children were of class 3 socio-economic status followed by $29.8 \%$ children belonging to class $5,19.7 \%$ belonging to class 1 and $10.4 \%$ belonging to class 2 and class 4 socio-economic status each.

In our study, merely a small percentage of mothers i.e. $9.9 \%$ belonged to 35-44 years of age group and 54.8\% were of $21-24$ years. In a study done by Madhu K, $60 \%$ of mothers were between 21 and 25 years of age. Maximum of mothers were of Hindu religion and minimum were of Christian. $44.6 \%$ were Muslims and $1.6 \%$ were Buddhist. In a study done by Chaudhary RN, ${ }^{4} 98.0 \%$ were Hindu, 1.5\% Muslim, Buddhist $.5 \%$ and Christian $0 \%$. In our study, $52.7 \%$ were living in joint family. In a study done by Maiti $\mathrm{A},{ }^{1} 59.1 \%$ of the mothers belonged to joint family. In our study, mode of delivery was normal in $68.3 \%$ of mothers. In a study done by Kumar $\mathrm{S}^{3}, 40 \%$ Mode of delivery was normal. In our study, maximum population preferred hospital as their mode of delivery. $93.5 \%$ mothers opted for hospital as their place of delivery. In a study done by Maiti $\mathrm{A}^{1}$, almost $93 \%$ deliveries were made at institutions. In our study, $23.4 \%$ mothers were illiterate. Only $2.4 \%$ mothers were professor/honours and $24.5 \%$ were having primary school certificate. In a study done by Singh S, ${ }^{8} 11.89$ mothers were illiterate and $22.38 \%$ were Graduate \& Above. In our study, only $28.8 \%$ were employed. $71.2 \%$ were housewife. In a study done by Alamirew MW, $45.1 \%$ were housewives. In our study, 58.3\% mothers started breastfeeding after 1 hour of baby birth. Breastfeeding within $1 \mathrm{hr}$ and $24 \mathrm{hr}$ was lower in study done by Kumar D ${ }^{9}$ and Chatterjee $\mathrm{S}^{10}$ where breastfeeding within 1 hour was only $6.3 \%$ and $14.54 \%$ and $32.6 \%$ within 24 hours and $23.3 \%$ as reported by Yadavannavar MC. ${ }^{11}$ In a study done by Khan $\mathrm{AM}^{12}$ in Delhi reported initiation of breast feeding within one hour of delivery was practiced by $37.2 \%$ mothers whereas it was only $13.6 \%$ in one study done by Sinhababu $\mathrm{A}^{13}$ from West Bengal.

In our study, $97.3 \%$ mothers gave colostrum to their child. $81.6 \%$ colostrum acceptance reported by Parmer $\mathrm{VR}^{14}$ and $35 \%$ as per study done by Wagh $\mathrm{SV}^{15}$ In another study $94 \%$ infants had received colostrums. In studies by Kumar $\mathrm{S}^{3}$, Maiti $\mathrm{A}^{1}$ and Alamu $\mathrm{TO}^{16}$ colostrum feeding was observed in $40 \%$, $74.83 \%$ and $94.5 \%$ children respectively. In our study, prelacteal feed was given in $57.3 \%$ children. In a study done by Divyarani $\mathrm{DC}^{2} 57.6 \%$ of them were given prelacteal feed. Our study findings were differed from a study done by Kumar $\mathrm{S}^{3}$ in New Delhi, where $90.9 \%$ mothers gave some pre lacteal feeds and a study done by Kulkarni $\mathrm{RN}^{18}$ in urban Navi Mumbai where, $36.1 \%$ of mothers gave pre-lacteals. In Kumar D 9 study,done in urban slum of Chandigarh out of 270 mothers, $40 \%$ gave pre-lacteal feeds. In a study done by Dakshayani $B,{ }^{19}$ in Mysore, study done among Hakkipikkis tribal population, $40 \%$ of them gave pre lacteals. In a study done by Surva Pathi S, ${ }^{20}$ in rural area of Orissa, $56.4 \%$ of babies had received pre-lacteal feeds. Only $15.2 \%$ infants received pre-lacteals in a study done by Sreeramareddy $\mathrm{CT}^{21}$ in Nepal. According to NDHS 2006, prelacteal feed is more in terai where 2 in 3 children receive them. ${ }^{17}$ Exclusive breastfeeding was done in $48.4 \%$ children for first 6 months in our study. As per the study of Pathi $\mathrm{S}^{20}$ in Orissa, only $8.6 \%$ mothers practiced EBF whereas, according to a study by Benjamin $\mathrm{AI}^{22}$ at Punjab and Aggarwal $\mathrm{A}^{23}$ at Delhi, it was $57.7 \%$ and $63.50 \%$ respectively. In a study from Vellore found exclusive breast feeding was done only in $11.4 \%$ of children under 6 months ${ }^{24}$ whereas in a study done by Mahmood SE, the prevalence of exclusive breast feeding to be $75 \%$.

In our study, $57.5 \%$ mothers continued breastfeeding during their sickness as well. In a study done by Divyarani DC, ${ }^{2} 50 \%$ mothers continued breastfeeding during their sickness. In our study, night feeding was practiced by $96.2 \%$ mothers. In a study done by Chaudhary $\mathrm{RN},{ }^{4} 15 \%$ of the mothers knew the importance of night feed but while coming to practice they were doing well. $90 \%$ mothers were practicing night feed. This was due to baby's demand even at night. In our study, $69.4 \%$ mothers informed their doctors about lactation status before obtaining prescription for drugs. In a study done by Divyarani DC, ${ }^{2} 71 \%$ mothers informed doctors about lactation status before obtaining prescription for drugs. In our study, $68.3 \%$ mothers didn't give water to their child during first 6 months. In a study done by Divyarani $\mathrm{DC}^{2}, 85 \%$ mothers gave water during first 6 months. Limitation of the study was as we used convenient sampling technique, the generalization of results will be difficult.

\section{CONCLUSION}

Knowledge regarding the proper feeding practice is good in the mothers, but still it can be improved. Proper education programs are the need of the hour for enhancing the quality and quantity of breast feeding. The importance of exclusive breast feeding, colostrums, night feeding etc should be provided to mothers. Since health care workers and doctors can influence this commitment, their positive attitude and knowledge is crucial in the prenatal period. Breast feeding awareness must be spreaded by workshops and health education programs.

\section{CONFLICT OF INTEREST}

None 


\section{REFERENCES}

1. Maiti A, Sarangi L, Sahu SK, Mohanty SS. An Assessment on Breastfeeding and Weaning Practices in Odisha, India. Am J Public Health Res. 2015;3(4):49-52.

2. Divyarani DC, Patil GR. Knowledge, attitude and practices of breast feeding among post natal mothers. Int J Contemp Pediatr. 2015;2(4):445-9

3. Kumar S, Sinha S, Sinha S, Singh V, Choudhary SK, Yasmeen T. Study regarding the feeding practice among mothers attending the immunisation clinic of a tertiary care centre. Int $\mathrm{J}$ Community Med Public Health 2019;6:273-6.

4. Chaudhary RN, Shah T, Raja S. Knowledge and practice of mothers regarding breast feeding: a hospital based study. 2011;9(3):194-200

5. Alamirew MW, Bayu NH, Tebeje NB, Kassa SF. Knowledge and Attitude towards Exclusive Breast Feeding among Mothers Attending Antenatal and Immunization Clinic at Dabat Health Center, Northwest Ethiopia: A Cross-Sectional Institution Based Study. Nursing Res Pract. 2017;2017:1-9.

6. Chakraborty N, Joardar GK. A study on infant and young child feeding practices among mothers attending the immunisation clinic of a tertiary care hospital, Kolkata, West Bengal. Int J Community Med Public Health 2020;7:4827-32.

7. Madhu K, Chowadry S, Masthi R. Breast feeding practices and new born care in rural areas: a descriptive cross-sectional study. Indian Journal of Community Medicine. 2009;34(3):243-6.

8. Singh S, Tiwari N, Malhotra AK. A cross-sectional study on exclusive breastfeeding practice among lactating females attending medical college, district Jhansi (U.P). Int J Med Sci Public Health. 2017;6(2):377-81

9. Kumar D, Agrawal N, Swami HM, Socio demographic correlates of breastfeeding in urban slums of Chandigarh, Indian journal Med. Science. 2006; 60; 461-6.

10. Chatterjee S, Saha S. A study on KP of mothers regarding infant feeding and nutritional status of Under 5 children attending immunization clinic of Medical college, The Internet Journal Nutrition and Wellness. 2008; 5 (1).

11. Yadavannavar MC, Patil SS. Sociocultural factors affecting breast feeding practices and decisions in rural women. International Jr of Plant, Animal and Environmental Sciences. 2011; $1(2): 47-9$

12. Khan AM, Kayina P, Agrawal P, Gupta A, Kannan AT. A study on infant and young child feeding practices among mothers attending an urban health center in East Delhi. Indian J Public Health. 2012;56(4):301-3.

13. Sinhababu A, Mukhopadhyay DK, Panja TK, Saren AB, Mandal NK, Biswas AB. Infant- and young child-feeding practices in Bankura district, West Bengal, India. J Health Popul Nutr. 2010;28:294-9
14. Parmer VR. KAP regarding Breast feeding at Chandigarh: Indian Jour. Public Health. 2000; 44; 131-133.

15. Wagh SV, Wagh SS, Raut MM, Dambhare DG, Sharma DA. A study of breast feeding practices in a Vidarbha region of maharashtra, india, Innovative Journal of Medical and Health Science. 2013;238-241.

16. Alamu TO, Atawodi SE, Edokpayi JN. Nutritional status of infants attending infant welfare clinic of Ahmadu Bello University, health service Samaru. Applied Sci Res. 2011;2(4):58-64.

17. Ministry of Health, New ERA and ORC Marco, Nepal Demographic Health Survey 2006; 171-176.

18. Kulkarni RN, Anjeneya S, Gujar R. Breast feeding practices in an urban community of kalam Navi Mumbai. Indian Journal of Community Medicine. 2004;29(4):179-80.

19. Dakshayani B, Gangadhar BR. Breast feeding practices among the Hakkipikki $\mathrm{s}$ in a tribal population of Mysore district Karnataka. Ethnomed. 2008;2(2):127-9.

20. Pathi S. Breast feeding practices in a rural ICDS block of Khallikote, South Orissa Indian Journal of Community Medicine. 2005;30(4):10-2.

21. Sreeramareddy CT, Joshi HS, Sreekumaran BV, Giri S, Chuni N. Home Delivery and new born practices among urban women in western Nepal. BMC pregnancy and child birth. 2006;6:27.

22. Benjamin AI, Zachariah P. Nutritional status and feeding practices in under-3 years old children in the rural community in Ludhiana, Punjab. Health and Population- Perspectives and Issues. 1993; 16 (1\&2): 3-21

23. Aggarwal A,Verma S, Faridi MMA. Complementary feeding Reasons for Inappropriateness in Timing, Quantity \& Consistency. Indian Journal of Pediatrics. 2008; 75 (1): 49-53.

24. Kishore SS, Kumar P, Aggarwal AK. Breastfeeding knowledge and practices amongst mothers in a rural population of North India: a community-based study. J Trop Pediatr. 2009; 55(3) :183-8.

25. Mahmood SE, Srivastava A, Shrotriya VP, Mishra PJ. Infant feeding practices in the rural population of north India. Family Community Med. 2012;19(2):130-5 